have felt obliged, at times, to undo the work of the surgeon, by deliberately cutting open the palate again, in order that an appliance may be fitted. The depressing effects of such a procedure must be very great ; and if such palates could be lengthened and rendered more floxible, this experience might be avoided and possibly the speech be rendered satisfactory.

Case VI. The patient was a girl of six, whose cleft inclucled the suft palate and about one-third of the hard palate. 'The suceess of the lateral flap in the first case led to its use here also. The result was entirely satisfactory, this velum being carried well back into tho pharynx, and the resulting slit in the palate being. elosed thoroughly by the Hiaps. About a week after the operation the suture nearest the bone was found to have eat out on one side. 'The patient was at once ethorized and a second sulure put in, a little deeper in the flaps. The patient was allowed to go to her home in the comnty at the expirition of three weeks, still wearing the sutures, and they were not removed until her return, ten weeks after the operation.

'The retention of sutures for so long a time would have been looked upon as impossible in the early days of the operation; and one is led to wonder that union was ever obtained, when the first suture was removed on the third or even on the second day, none being left longer than a week. In the first of these three catses the sutures, which were, in all cases, of copper wire, silvered, were not removed until eight weeks after the operation, and in the third case the time was abuut tivo weeks. In no case was there the least disturbance that could be attributed to their presence. Probably the time allowed to elapse in these cases is umecessarily long, and may result in more thickening than is needed, and in the future I shall remove them in from two to three weeks, in case union is nssured.

Case VII. F. R., a boy, sixteen years old, had a cleft running from the uvula half-way through the bony palate. Sume years ago he applied at a hospital to have the operation done, but was dissuaded, on the ground that the results were not salisfactory. 'The operation was identical with the list mentioned, and without incident. He pemained in leed but a day or two, and soon left for his home in is suburb, coming into the city onee or twice weekly, to report progress. His speech improvel from the beginning, but more repidly after the removal of the sutures, which sometimes slipped around and impeded the action of the tongrae.

All the operations were perforwed in the semi-upright position, and with ether narcosis. No great amount of hemorrhage was met with when the incisions were made, slight pressure eusily controlling it. Au ordinary mouth-gag was used, the tongue-depressor being sometimes necessury. The wire sutures were pulled through the flaps by meins of loops of silk thread attached to long-handled curved needles. Hot salt-solution was used as a moutb-wash, and the patients vere encouraged to drink milk and to take as much as possible of other liquid and semi-liquid foods.

'The bone left bare by the turning of the thaps bo. came covered with swollen tissue and granulations within a few days, and gave no trouble whatever. A considerible fold of tissue is left in the middle of the roof of the mouth, and just how far this will be flat. tened down timo alone can tell. I do not think it will be of any disalvantage, unless possibly in titting an artilicial denture.

Much might be written about the exercises, vocal and othor, which should bo employed after the operation. All those acts which require the closing off of the nasal space from the mouth are the most important. Among these are the blowing out of $a$ candle by a strong puff of the breath; the bluwing of a lead pencil or similar object forcibly from the lips, etc. In order to follow the improvement made by theses patients, and with the idea that the defects in speech may be made known to the patient himself, and thus corrected more intelligently, I havo taken phonographic records of the speech of each one before the operation, and at different times after. 'The value of this procedure will be determined only after a wider experience.

DISCUSAION.

DR. H. A. BAKkR: It is not my purpose to come here to criticise a surgical operation on the palate, as perhaps most practitioners would who make appliances for the same effect. (If course, any one would sity if an opreration is a saceess in improving speech there would be no argument on the side of appliance; of conrse, it would be preterable to any appliance that could be inserted for that purpose. I know that this operation was done many years ago by eminent surgeons, and, of course, the cuses that l have seen have been cases that have not been a suceess, because if they had been they would not have come to me; but I do not propose to discuss the merits or demerits of an oper.ation, because many of you here are eminent surgeons, and operations may have come ni) that 1 am not familiar with. I saw three patients Dr. Smith operated on, and in one of them it seemed that there was a chatnce of a great deal of improvement. I do not, know but that everything was done that could be done in that case. It was a child six years old. The child had habits to overcome aside from the deformity, and most of those cases do have habits in their speech, that is, hitching in speech. The ilea is, that in initating speech they initate as well as they can, and in doing so they do not use their muscles correctly, because they have not the organs to use eorrectly; and in putting in an appliance or performing an operation, they lave a great deal to learn and overcome to correct that speech. Whether that can be done is a guestion. As I saill before, many cases have come to me for correction that have beon operated on. Some of them have been a surgienl suceess, that is, there would be an entire closure of the palate. In those cases we hatve to cut them open, and put in a certain appliance. ()f course, if a surgeon operates and has not male a success of it, the patient is wor:e off than if no operation had heen done. 'l'hey' must go through almost as severe an operntion to undo the former operation as to have had it done in the first place.

As fur as appliancess being a snccess, there is no furllues question about that. That has been demonstrated time and time again; but, of comrse, an appliance is an objection. 'llhey have always got to wear an appliance if liey once have one; and at the same time I find they are pretty willing to if they get any benefit from it.

SOME OF 'THE SIMPLAR THSI'S FOR IE'TEC'TING ERRORS OF REFRACTION AND INSUFFICILNCILS OW THE OCULAR MUSCLLS.'

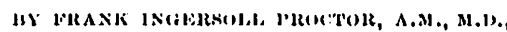

Assistemt Ophthalmic Suryeon, Mlassrechusetts Charituble Eye anel Ear linjirmary, Instructor in Ophthalmology, Harvard school of Veterinary Medicine.

'l'uk importance of correcting ocular errors for the relief of headache and various other functional neuroses has been emphasized by many writers. In tho last ten years numerous articles have been published, the titles of a few of which illustrate the direction in which the subject has been investigited."

'These articles treat of the relation of ocular defects

1 Read before the Warron Club, Boston, Fubruary 5, 1895.

2 Sou llst at end of tho artiolo. 
to headuche, and the numerous cases reported prove conclusively that in many instances headache, vertigo, neuralgia and other nervous symptoms are due to some defect of the eyes.

As regards the percentage of headaches due to this cause, it is diflicult to make even an approximate estimate; some of the writers referred to consider that eye strain produces more headaches than all other causes combined, and even the most conservative agree that it produces more than any other one cause.

In view of all that has been said and written on this subject, it might be expected that one of the first steps taken by a physician when meeting with these symp. toms would be to examine the eyes, to determine whether there were any error of refiaction or lack of bulance of the ocular muscles. 'That such a course is the exception, and that an examination of the ocular condition, if undertaken at all, is often the last resort, may be due to the following reasons :

(1) There may be nothing to direct the physician's attention to the eyes. In many of these cases the sight is normal, or nearly so; the patient sees clearly, the eyes themselves may vecasion him no discomfort; and he usually attributes his symptoms to some other cause, as to indigestion or overwork, for example.

'The following case is an illustration. Dr. R. B., a dentist, thirty-eight years old, consulted twe November 1,1894 , with this history: He has practised dentistry fifteen years, and has always been able to work and use his eyes with porfect comfort. On Sundays and holidays, however, when he dioes no work, he almost invariably suffers with headache, which becomes more severe as the day advances, and is often accompanied by nausea and vomiting. Otherwise, he has always been in good health. Recently he was examined by his brother, a physician, who found nothing to account for these attacks. The ey es were tested, and hypormetropia of $1.25 \mathrm{D}$. was discovered, for which correcting glasses were prescribed, to be worn constantly. 'I'wo months later he returned and reported that since wearing the glasses he had been entirely freo from the headache and nausea with which he formorly suffered nerirly every week.

(2) Should tho physician suspect the existence of some ocular defect, in most cases he possesses noither the apparatus, nor sullicient familiarity with the methods employed, for making a positive diagnosis. 'The exhaustive articles on refraction in the text-books are more or less confusing, and to carry out their suggestions would necessituto procuring an equipment wholly incommensurate with the needs of the general practitioner.

Dr. Valk, one of the writer's referred to at the outset, has appreciated the need of a ready test, alapted to the use of physicians in examining the eyes for purposes of diagnosis. He describes at length a unothod which, he claims, will meet every requiroment. "Retinoscopy," he says, "is the name of this simple test." Referring to this, Dr. Swan Burnett, of Washington, remarks: "It (retinoscopy) has been called a simple test, and so it is; but, simplo us it is, it cunnot be mastered without painstaking care as to the smaller details, und cousiderable experience is necessury beforo it cau be executed with the rupidity and certainty of which it is capable . . and which aro anong its recommendations to the practitioner."

A few quolations from a recent articlo ${ }^{8}$ by Dr.

8 De Schwodnitz : Diseases of tho Eyo, Philadolphia, 1893.
Edward Jackson, of Philadelphia, which furnishes an excellent description of retiuoscopy, give un idea of some of the difficulties encountered in applying this test. "Retinoscopy ... is a method of determining the refraction of the eye by observing the direction in which the light appears to move across the pupil, when the mirror by which light is thrown upon the eyo in the dark room is rotated." After considering its use in myopia, hypermetropia and emmetropia, he describes its application in regular astigmatism: "The principles involved and the nethods to be employed are essentially the same as in myopia or hypermetropia; but the refraction has to be deternined in the principal meridians, instead of in any meridian indifferently, as it can be where all meridians are alike. .. The direction of either of these principal meridians is revealed by the area of light in the pupil assuming the form of a more or less distinct band of light, extending across the pupil in the direction of this meridian, when its point of reversal is approached. When the band-like appearance is most noticeable, it is easy to cause its apparent movement from side to side; but it is more difficult to distinguish the movement in the direction of the leugth of the band. Still, this latter movement is the one especially to be watched und its reversal point to be determined."

The chief objections to retinoscopy as a test to be used by physicians gonerally for detecting ocular errors are -

(1) Its successful cmployment requires considerablo experience.

(2) In the majority of cases the amount of error is small; and it is in these cases that retinoscopy is least reliable, even in the hunds of an expert.

As retinoscopy presents these difficulties, and inasmuch as no simpler nethod is suggested in the article referred to, I will attempt to describe briefly some tests, which, without previous experience on the part of the plyssician, may bo applied in practice for determining the existence of such ocular errors as may. give rise to the nervous symptoms bofore mentioned.

'The errors of refraction are, $(a)$ astigmatism, (b) hypermetropia, (c) myopia.

The muscular insufficiencies are, $(d)$ exophoria," (e) esophoria, $(f)$ hyperphoria.

'The necessary apparatus ${ }^{6}$ consists of test letters and an " astigmatic chart," two convex trial lenses (.50 1$).$ and .75 D.), a candle, and a glass rod about the size of a pencil.

The test letters are placed twenty feet from the pa. tient, and on a level with his eyes. The eyes should be oxamined separately, one boing covered while the other is tested. If the curd is in a good light and the eye is uormal, the patient will see each letter distinctly. Ability to do this, however, does not exclude hypermetropia.

I'est for Hypermetropia. - With tho test card arranged as before, the oye to be examined is directed at the letters, and the trial lens .50 D. is held before it. If the pritient sees the letters as distinctly with the lens as without it, there is hypermetropia of at - 'lihis classification of muscular insufliciencles is of comparatively recent date. Tho terms are dothed by thoir originntor, Dr. G. T. Stevens, as follows: " Esophorih, $h$ tending of tho visual lines inward, Exophoria, a tending of the visund lines ontward i Hyperphoria, tendency of the right or left vinual line above its fellow." Funct. Nerv. 1is., p. 102, New Xork, 1887, G. 'I'. Stuvens, M.J)., l'h.1). "Thls apparatus may bo obtalned from any opticlan. At my suggestion, Messrs Miller und Welch, 38 West Street, have prepared
some pocket cases containing tho trial lenses and a suitable glass rod. 
least .50 D. The .75 D. lens is then substituted for the .50 D. If the letters are still seen distinctly, the hypermetropia is at least .75 D.

These tests simply demonstrate the existence of hypermetropia. 'There may be latent hypermetropia which is not shown by these tests; but if the patient can read the letters through either trial lens, he is hypermetropic in that extent, at least.

T'est for Astigmatism. - 'The astignatic chart is sub. stituted for the test letters and the eyes are examined separately, as before. The patient is directed to observe carefully the radiating lines on the chart. If the eye is normal, the lines all appear equally clear and distinct, and of a uniform shade. But if some appear black and distinct, while others are more or less blurred und indistinct, the eye is astigmatic. The other eye is then tested in the same wanuer.

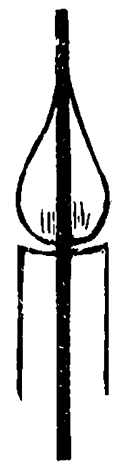

Fig.1.

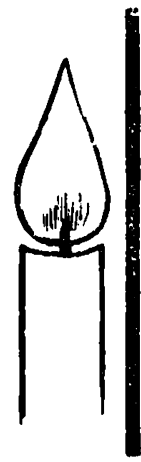

Fig.2.

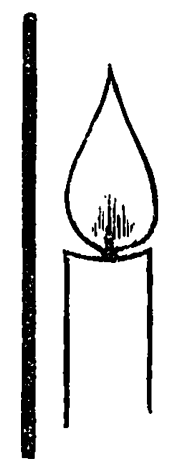

Fig.3.

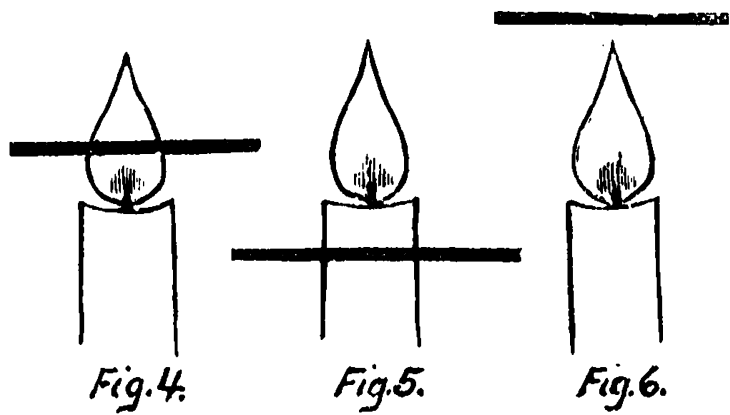

It may happen that none of the lines are seen distinctly at the given distance, twenty feet. In this case the card is grudually brought nearer to the patient until some of the lines are seen distinctly. If now some of the lines appear to be more distinct than others, the eye is astigmatic; but in this case there is either some additional error, or possibly some disease of the eye.

('Tests for myopia have been omitted for the following reasons: In this country simple myopia is much less prevalent than hypermetropia and astigmatism; patients who are myopic are usually aware that their eyesight is defective; and finally, myopia is far less productive of nervous symptoms than are hyper. metropia and astigmatism.)

Tests for Muscular Insufficiencies (Maddox). - In these tests better results will be ohtained if the room is partially darkened. 'lo test first the balance of the lateral muscles. A lighted candlo is placed twenty feet from the patient, and on a level with his eyes. 'The patient's left eye being covered, he looks at the cundle with his right eye. The glass rod is now held horizontally before this eye, whereupon a vertical line of light is seen in place of the candle flams. While the rod is held in this position before the right eye, the left eye is uncovered. The left eye now sees the candle flame, the right eye sees the line of light. If the line of light passes directly through the flame (Fig. 1), the lateral muscles balance. If the line is to the right of the flame, there is esophoria (Fig. 2). If the line is to the left of the flame, there is exophoria (Fig. 3).

'To test for vertical deviation. 'The left eye is covered, and the rod is held vertically before the right eye. A horizontal line of light is now seen in place of the candle flame. The left eye is now uncovered and sees the flame, while the right eye sees the line of light. If there is no vertical deviation, the line of light will pass directly across the flawe (Fig. 4). If the line is below the flame, there is right hyperphoria (Fig. 5). If the live is above the flame, there is left hyperplioria (Fig. 6).

In these tests of the muscular equilibrium, the degree of error is measured by the distance between the line of light and the cundle flame. In any case it should be borne in tnind, as Dr. DeSchweinitz remark8, that "an absolute balance of the exterual eye muscles is quite as rare as emmetropia, and hence small errors of the lateral muscles are often unimportant."

\section{IIST OF REFERENCES}

Bickerton, 'T. H. Headache due to errors of the refractive media of the eye. Iancet, lonclon, 1867, ii, 303-305.

Murtin, G. Migraine et Astigmatisme. Aunales d'oculintiçuo, Brux., 1888, xcix, 24-4ti.

Kanney, A. L. Eye strain as a canse of headache and neuralgin. New York Medienl Record, 188!, x xxv, 67:3-1i8t.

Wylie, 1). 13. Hypermetropic: istigmatism and its rejation to nervous sick headaches, with report of a eise. Memphis Medicnl Monthly, 18!90, x, 8-10.

Kroide, G. N. Functional nervous disturbances cured by the correction of errors of refraction. Medical and surgical Reporter, Phila., 18\$0, Ixii, 16iti-16x.

Valk, K. Eye strain, its causes and symptoms, and an oasy, necurnte and inexpensive method for its detection by tho goneral practitioner. Gaillard's Medical Journal, N. Y., $1890,1,6+7-650$.

Bliss, F. F. Headache and its relation to oye strain. A review of 100 chses of persistent headache cured by correcting errors of refraction and muscular defects, with conditions and results. Columbus Medicul Journal. I88!9-90, viii, :3!)2-4(1)1.

Hotz, F. C. The nature of eyo strain and its relintion to headaclie and other nervous disordetrs. Northwest Medical Jour. unl, Minnenpolis, 1890, x viii, 185-188

Baldwiu, B. J. Healathe and neumalyia the result of refrac:tive crrors. Trunsictions Alabama Medical Association, Montyomery, 18:0, 33:2-:-2t(5.

Eales, 11. On headiches and other results of ocular strain. 'The Middlemoro Lecturo, Birmingham Medical Review, 18!1, $\mathrm{xxix}, 65-87$.

Callau, P. A. Migraine and functional headuches from oyo strain. Journal Amorican Medical Association, Chicago, $18 ! 11, x v i, 435)-438$.

St. Julu, S. B. Eyo strain as a causo of reflex irritation. Proeoedings Connecticut Medical Society, Briclgeport, 1890, iv, No. 3, 131-1+2.

Andrews, J. A. Functional hoadache from eye strain in children. New York Midieal Jomruat, 18!)1, $41-46$.

Mittendorf, IV. F. One thousand rases of oculat headaches

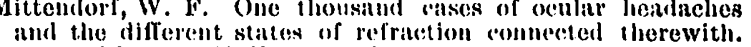
Medical Record, N. Y.. 1s!11, xl, $5-$ -

Chisholm, J.J. Astigmatism: a very (ommonn and often umreeognized cause of headache. International Clinic, Philadolphit, 18!1, i, 3:28-33!!.

Cheney, F. L. Weu'ar heidaches. Boston Medienl and Surgicul journal, 18!2, ex xvi, 10-12.

Hern, J. The elrect of correcting errors of refraction in epileptics. British Modical Journal, London, 1893, ii, 732. 
Callam, P.A. Pliysical and psychical disturbances induced by eye strain. Virginia Medical Montlily, Richmond, 189)3-94, $\mathrm{xx}, 436-4+11$.

Sangree, E. J3. Tic douloureux from visual defect. Medical News, Plibalelphia, $1893,1 \times \mathrm{xi}, 572$.

Ilawley. C. W. Some ocular reflexes other than headaches. Anmals of Ophthalmology and Otology, st. Iouis, 1893, ii, 1611 lit.

Walton, G. J. and (anter, C. F. Eye strain and headache. Mediaral News, Philadelphia, 18:12, lx, 30:1-312.

Seguin, E. C. Eye strain and its relation to cerebral hyporinmia. New York Medienl Journal, 18!)', Ivi, (617-6i19.

Gouli, G. M. Low degrees of eye strain a source of systemic disturbances. British Medienl Jourmal, london, 18!4, ii, $503-i)(15$.

Owen, .J. S. Chronic headiche relieved by correcting latent ocular museular irregularities. Medical Age, Detroit, 1894 $\mathrm{xii}, 431-434$.

Webster, b. Asthenopia following acute nephritis and diphtheria.relieved by colrecting hypermetropia and astigmatism. Archiv. Pediatrises, N. Y., 1894, xi, 364

\section{elinital Department.}

\section{A CASE OF ILARYNGEAL DIPIITHERIA 'TREA'TEL) BY ANTITOXIN.1}

BY 1. B. I,UX1), M.D.,

Surgcon to Out-1'atients, Boston City Hospital.

Tux following case is of interest for three reasons, namely: the extent to which disease had progressed before the antitoxin treatment was begun, the large amount of antitoxin which was required before the symptoms began to subside, and the severity of the after-effects. 'To these may be added the fourth, the unfavorable nature of the patient's surroundings.

On March 13 th I was requested by Dr. F. R. Tower to operate upon a case of laryngeal stenosis occurring in his practice as dispensary physician. The child had been first seen by Dr. 'Iower on March 7th, the parents informing him that he had had a cough for two or three days. There was no sore throat, and the child was thought to be suffering from a tracheitis or bronchitis of the larger bronchi. About March 11th, a inembranous deposit had formed upon the tonsils, and a diagnosis of membranous croup was made. On Murch $12 \mathrm{~h}$, the child was restless and the respiration somewhat obstructed, retraction of the sliprasternal notch being marked. On March 13th the nurse found the child sitting up in bed, with marked cyanosis, and obstruction to respiration. At 11.30 A. M., I found a boy threo years old, well developed and nourished, in a critical condition from obstruction of the respiration. Intubation was performed with marked relief of dyspnea. The tonsils were found to be covered with discrete patches of a not very thick white membrane. On the right side of tho neck were enlarged and softened glands, evidently tubercular, a sinus discharging a small anount of pus, and severul scars.

At 3.50 P. м. 15 c. c. of Gibier's antitoxin (marked 1-80,000) was injected unter the skin of the thigh. The temperature at that time was $102.4^{\circ}$, and the pulse 130. At 4 A. $\mathrm{s}$. of March 14th, 10 c. c. of antitoxin were given. At 10 A.M. a culture was taken from the pharynx, which showed the presence of the bacilli of diphtheria. 'There was now but little obstruction to the respiration, but as the child had been able to take but little nourishment and stimulant

1 Rend boforo the Clinical Section of tho Suffolk J)istrict Medica Soclety, Aprll 17, 1805. during tho night, rectal alinentation was hegun. As the temperature at $4 \mathrm{p}$. $\mathrm{M}$. was still high $\left(102^{\circ}\right)$ and there was no apparent chauge in the gencral or local condition, 25 c. c. of antitoxin were administered. During the night the tempernture fell to $99.2^{\circ}$, but rose rapidly during the following morning till 10 A. M., when it was $103.4^{\circ}$. The child's greneral condition, however, was good. Considerable milk and whiskey was taken by mouth during the early morning; and on tho 15 th tho child slept nearly all day, breathing quietly. The tube was coughed upl at 3.45 P. M., and it was not necessary to replace it. During the night, however, the respiration gradually becames obstructed, and the next morning, the 16 th, it became necessary to replace the tube, as the child was becoming exhausted by its efforts to breathe. 'The tonsils aud palate were swollen and red, but the membrane had nearly disappeared, only a fow small shreds still remaining udherent. 'line severe dyspmea, however, showed that either fresh membrine had formed in the trachea, or that it had not become detached there, as it had in the pharynx. At 3.45 P. M., 25 c. c. of antitoxin were given. The child was able to take milk and whiskey fairly well in spite of the presence of the tube, so that it was possible to discontinue the nutrient enemata.

On March 17th the child had a good day, but as the temperature still remained high $\left(101.5^{\circ}\right)$, it was thought best to give another dose of antitoxin ( $25 \mathrm{c.}$ c.). At $6 \mathrm{P}$. M. the tube was coughed up, and the child was thereafter able to do without it.

During the 18th and morning of the 19th the temperature gradually fell; but on the forenoon of the 19 th an eruption resembling measles appeared on the fuce, neck and arms, with intense itching. The child rofused to taste nourishment, and was very restless. The itching was relieved by a wash of carbolic acid $(1-100)$.

On the 20 h there was noted swelling and tenderness of the cervical lymphatic glands, and the skiu about the sinus in the neck was red and swollen. The rash disappeared, except where the child scratched himself, bringing out urticaria-like wheals.

On March 2 rst the rash appeared in blotches, most marked on the face and legs. The temperature remained abovo $102^{\circ}$, and no nourishment was taken by the wouth.

On March 22d, the appetite returned in some degree; the rash was still present on this and the following day.

On March 24th the rash had nearly disappeared, but the child's temperature was still higher (over $103^{\circ}$ ); very little nourishment was taken, and the uutrient enemata were not retained.

On the 26th, the other conditious remaining about. the same, the child was noticed to be passing very little urine. Examination of a specimen by Dr. Greene showed it to be free from albumin. Sweet spirits of vitre were given one-half drachm every four hours.

On March 27th the morning and evening temperatures were $104.8^{\circ}$, but the child took a little more milk.

On the 27 th the evening temperature reaclied $105^{\circ}$, and the patient was covered all over with a rash, confluent over the body, and looking like scarlet fever. On the arms and face, however, the eruption was macular. Very little milk was taken, and the child was very weak, restless and uncomfortable. 